\title{
Ultrasonographic Study of Placenta Positioning and Its Significance in Parturition among Women in Delta State
}

\author{
* L.E. Chris-Ozoko ${ }^{1}$, I. Moses ${ }^{1}$ and A.O Naiho ${ }^{2}$ \\ ${ }^{1 .}$ Department of anatomy, faculty of basic medical sciences, Delta state university, Abraka, Delta state, Nigeria. \\ 2. Department of physiology faculty of basic medical sciences, Abraka, Delta state Nigeria
}

\begin{abstract}
Ultrasound is a useful adjunct to the physical examination, particularly in obstetrics patients. By ultrasonography we visualize the placenta position in-situ and describe various positioning of placenta in the uterus. The placenta is positioned at different sites in the uterus which can predict methods of parturition. The objective of this study is to investigate the different positions of placenta as seen in ultrasound scan and it's significant in parturition among women in Delta state. The study comprises of 150 women who registered for antenatal care at Eku Baptist Hospital Eku, Delta state, and have given birth in the Hospital. The pregnant women were examined with ultrasound scan which determined the positions of the placenta at the radiodiagnostic department. The different positions such as anterior, posterior, fundal and previa were recorded. The methods of deliveries were also taken note of in the pre-maternal labour forms in obstetrics/gynaecology department and health record office of the Hospital. Data were presented as mean and standard deviation; data were analysed using statistical package for social science (SPSS). The cases of previa were related to the type of delivery out of 28 cases of previa 18 women delivered by caesarean section and 10 had normal delivery. 10 out of all are previa type I, 7 are previa type II, and 11 are previa type III. All type III cases delivered through caesarean section.
\end{abstract}

Key words: ultrasonography,placenta positions, placenta previa, ceaserean section and normal delivery.

\section{Introduction}

Ultrasonography is an ultrasound-based diagnosis imaging technique used for visualizing internal body structures including liver, kidney, pancreas, uterus, breast, prostrate, stomach e.t.c. for possible pathology or lesions. Obstetric sonography is commonly used during pregnancy and is widely recognized by the public. Debose, (1). However, ultrasound is a useful adjunct to the physical examination, particularly in obstetric patients or in patients with abnormal pelvic examination findings. It is a simple procedure based on sound wave transmission that uses pulsed ultrasonic wave at frequency exceeding $20,000 \mathrm{~Hz}$ (formerly cycles per second) by way of a abdomen (abdominal scan) or a vaginal probe (transvaginal ultrasound). Mechanical energy is converted into electrical impulses, which in turn are amplified and recorded on an oscilloscope screen while a photograph or video recording of the pattern is taken. Suzanne et al., (2).

Ultrasonographic evidence of the developing placenta can be seen as early as 6 weeks of gestation. It appears as an area of high-level echoes surrounding a border representing the developing gestational sac. The echoes represent the chorionfrondosum, which develops into the definitive placenta. Approximately 12 weeks of gestation the structures of the placenta can be more clearly discerned. Shweniet al.,(3).The placenta is a membranous vascular organ that develops in uterus of female during pregnancy, lining the uterine wall and partially enveloping the foetus, to which it is attached by the umbilical cordPetraglia. et al.,(4). It is a temporary organ required for the development of the embryo and foetus, like a young tree putting its root down deep into the ground as it grows, the placenta also does the same thing into the uterus as gestational age increases. Steeret al.,(5).Ultrasonographically, the placenta is homogenously echogenic compared to the hypoechoicmyometerum and the anechoic amniotic fluid, and uniform thickness. By application of ultrasound the exact position of the placenta in the uterus can be determined,Rehab. et al., (6).The implantation site (whether anterior or posterior) the distance of the lower placenta margin from the internal cervical Os and the relationship between the presenting part and the placenta margin are important sonographic findings. These findings may predict clinical outcome in placenta previa.Chourabet al., (7).

\section{Materials And Methods}

The study comprises of 150 women who registered for antenatal care at Eku Baptist hospital Eku, Delta state, and have given birth in the hospital. Approval from the ethical committee of the hospital was obtained. The pregnant women were examined with ultrasound scan to determine the positioning of the placenta at the radiodiagnostic department. The different positions such as anterior, posterior, fundal, anterofundal, posterofundal and previa, were recorded. The type of delivery were also taken note of in the pre-maternal labour 
forms, in obstetrics/gynaecology department of the hospital, delivery through caesarean section and normal through the cervix, were all documented.

\section{Procedures}

Women attending the antenatal clinic in the Department of Obstetrics and Gynaecology, who were referred for routine ultrasonography, Patients were scanned using mindray ultrasonography (USG) machine with a trans- abdominal probe. Patients were asked to maintain a full bladder, for obtaining a better window (acoustic window) for the USG examination.

\section{Scanning technique}

With the patients in a supine position, jelly was applied over the abdomen and examination was carried out using the probe with the USG machine. Different positions of the placentas were recorded during performance of the examination, and all were subsequently observed during delivery. All ultrasound examinations were performed by a certified radiologist.

Data were analyzed using statistical package for social science (SPSS).

\section{Results}

\begin{tabular}{|c|c|c|c|c|c|c|c|c|c|c|c|c|c|c|c|}
\hline \multirow{3}{*}{$\begin{array}{l}\text { Mother } \\
\text { Age } \\
\text { group }\end{array}$} & \multirow{3}{*}{$\begin{array}{l}\text { Number } \\
\text { of } \\
\text { Cases }\end{array}$} & \multirow{2}{*}{\multicolumn{2}{|c|}{$\begin{array}{l}\text { Method } \\
\text { of } \\
\text { Delivery }\end{array}$}} & \multicolumn{12}{|c|}{ Position of placenta } \\
\hline & & & & \multicolumn{2}{|c|}{ Anterior } & \multicolumn{2}{|c|}{ Posterior } & \multicolumn{2}{|c|}{ Fundal } & \multicolumn{2}{|c|}{ anterofundal } & \multicolumn{2}{|c|}{ Posterofundal } & \multicolumn{2}{|c|}{ Previa } \\
\hline & & CS & ND & $\mathbf{C S}$ & ND & CS & ND & $\mathbf{C S}$ & ND & $\mathbf{C S}$ & ND & CS & ND & CS & ND \\
\hline 17-21 & 18 & 6 & 12 & 3 & 5 & 1 & 3 & $\mathbf{0}$ & $\mathbf{0}$ & $\mathbf{0}$ & $\mathbf{0}$ & $\mathbf{0}$ & $\mathbf{0}$ & 2 & 4 \\
\hline $22-26$ & 39 & 6 & 33 & 4 & 15 & 1 & 11 & $\mathbf{0}$ & $\mathbf{0}$ & $\mathbf{0}$ & 4 & $\mathbf{0}$ & $\mathbf{0}$ & 1 & 3 \\
\hline $27-31$ & 54 & 18 & 36 & 6 & 16 & 1 & 13 & 1 & 2 & 1 & 3 & $\mathbf{0}$ & 1 & 9 & 1 \\
\hline $32-36$ & 26 & 9 & 17 & 2 & 7 & 2 & 9 & $\mathbf{0}$ & $\mathbf{0}$ & $\mathbf{0}$ & $\mathbf{0}$ & 1 & $\mathbf{0}$ & 4 & 1 \\
\hline 37> & 13 & 6 & 7 & 2 & 1 & 1 & 5 & 1 & $\mathbf{0}$ & $\mathbf{0}$ & $\mathbf{0}$ & $\mathbf{0}$ & $\mathbf{0}$ & 2 & 1 \\
\hline TOTAL & 150 & 45 & 105 & 17 & 44 & 6 & 41 & 2 & 2 & 1 & 7 & 1 & 1 & 18 & 10 \\
\hline
\end{tabular}

Table 1: number of cases examined by ultrasound showing their placenta site and delivery method

\section{$\mathrm{CS}=$ Caesarean section. $\mathrm{ND}=$ Normal delivery .}

Table 2. Distribution of placenta position and method of delivery

\begin{tabular}{|l|l|l|l|l|}
\hline SN & Placenta position & ND & CS & TOTAL \\
\hline 1 & Anterior & 44 & 17 & 61 \\
\hline 2 & Posterior & 41 & 6 & 47 \\
\hline 3 & Fundal & 2 & 2 & 4 \\
\hline 4 & Anterofundal & 7 & 1 & 8 \\
\hline 5 & Posterofundal & 1 & 1 & 2 \\
\hline Total & & 95 & 27 & 122 \\
\hline
\end{tabular}

ND = Normal delivery, $\mathbf{C S}=$ Caesarean section .

Table 3: Relationship between types of delivery and previa

\begin{tabular}{|l|l|l|l|l|l|}
\hline S/N & $\begin{array}{l}\text { Types of } \\
\text { Delivery }\end{array}$ & Previa I & Previa II & Previa III & Total \\
\hline 1 & CS & 3 & 4 & 11 & 18 \\
\hline 2 & ND & 7 & 3 & 0 & 10 \\
\hline Total & & 10 & 7 & 11 & 28 \\
\hline
\end{tabular}

$\mathbf{C S}=$ caesarean section $\quad \mathbf{N D}=$ Normal delivery.

Table 4; Relationship between placenta positions with previa

\begin{tabular}{|l|l|l|l|l|}
\hline S/N & PREVIA GRADES & ANTERIOR & POSTERIOR & TOTAL \\
\hline 1 & PREVIA I & 7 & 3 & 10 \\
\hline 2 & PREVIA II & 2 & 5 & 7 \\
\hline 3 & PREVIA III & 4 & 7 & 11 \\
\hline TOTAL & & 13 & 15 & 28 \\
\hline
\end{tabular}

Table 5: Percentage distribution of parity

\begin{tabular}{|l|l|l|l|}
\hline S/N & PARITY & N & PERCENTAGE (\%) \\
\hline 1 & P1 & 71 & 47.33 \\
\hline 2 & P2 & 26 & 17.33 \\
\hline 3 & P3 & 17 & 11.33 \\
\hline 4 & P4 & 15 & 10 \\
\hline 5 & P5 & 12 & 8 \\
\hline 6 & P6> & 9 & 6 \\
\hline
\end{tabular}




\begin{tabular}{|l|l|l|l|}
\hline TOTAL & 150 & 100 \\
\hline
\end{tabular}

$\mathrm{N}=$ Number. $\quad$ Table 6; Distribution of parity and previa

\begin{tabular}{|l|l|l|l|}
\hline S/N & PARITY & PREVIA & PERCANTAGE (\%) \\
\hline 1 & P1 & 13 & 18.31 \\
\hline 2 & P2 & 5 & 19.23 \\
\hline 3 & P3 & 3 & 17.64 \\
\hline 4 & P4 & 3 & 20 \\
\hline 5 & P5 & 2 & 16 \\
\hline 6 & P6> & 2 & 22.22 \\
\hline TOTAL & & & 100 \\
\hline
\end{tabular}

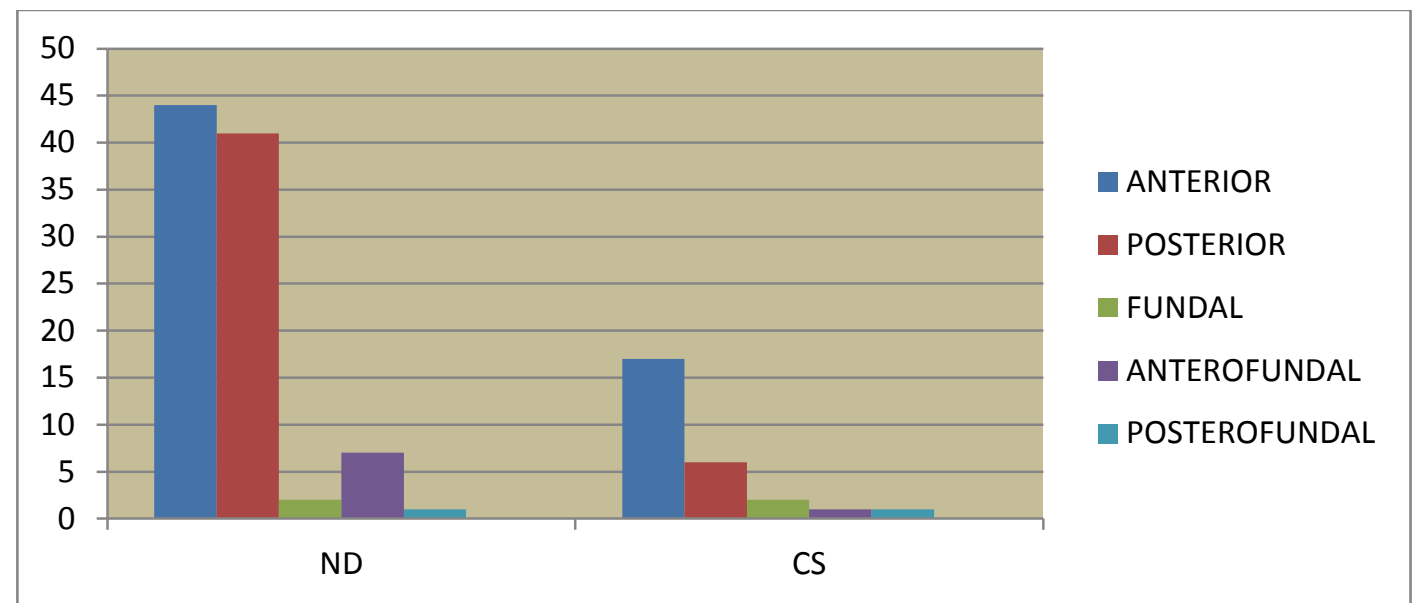

Fig 1.A graph of maternal placenta positions with type of delivery.

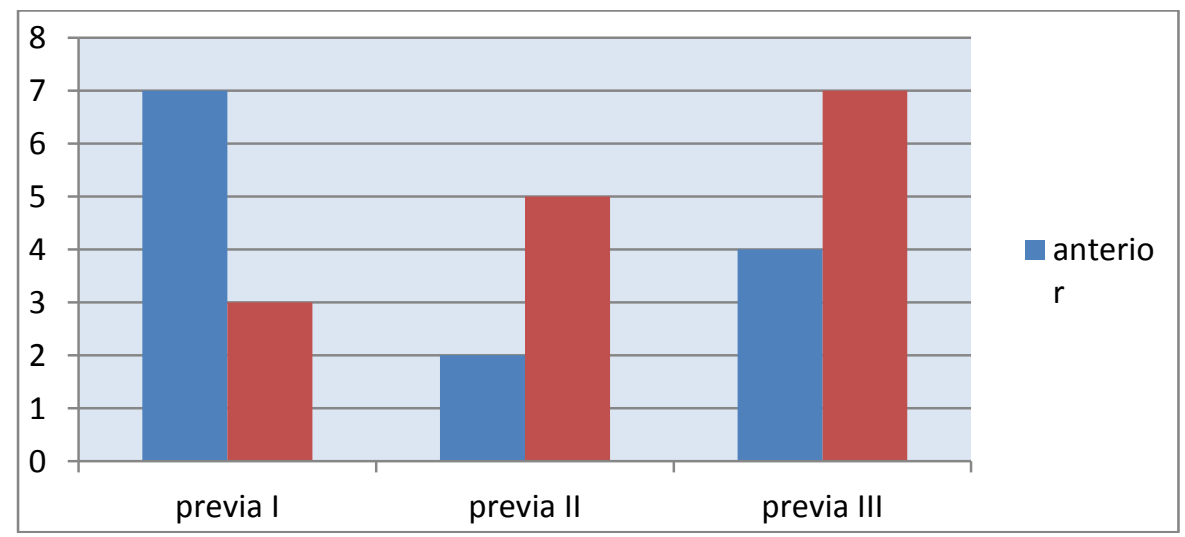

Fig 2.A graph of placenta position with previa.

\section{Observations}

The number of cases examined and the different placenta position with mode of delivery were shown in table 1. Table 2 shows the distribution of placenta position and the method of delivery. From the table, mothers who delivered through normal delivery with anterior, posterior, fundal, anterofundal and posterofundal position are 44, 41, 2, 7 and 1 respectively, while mothers who delivered through caesarean sections with anterior, posterior, fundal, anterofundal and posterofundal position are 17,6, 2, 1, and 1 respectively. The number of mother who delivered normally irrespective of the placental previa are 95 ,caesareansectionare 27.

Table 3 shows the relationship between the type of delivery and previa and it can be deduced that, there is higher case of placenta previa with caesarean section compared to previa with normal delivery.

Table 4 shows the distribution of the types of previa with placenta position. Mothers with anterior placental positions with relation to previa are less than mothers with posterior placental position.

Table 5 shows the percentage distribution of parity among number of maternal birth where P1, P2, P3, $\mathrm{P} 4, \mathrm{P} 5$, and P6> are presented with the number of parity and its percentage are $71(47.33 \%), 26(17.33 \%)$, $17(11.33 \%), 15(10 \%), 12(8 \%)$, and $9(6 \%)$ respectively. Mothers who have given birth to one and two child (P1 and $\mathrm{P} 2$ ) has the highest percentage of $47.33 \%$ and $17.33 \%$ with a frequency of 71 and 26 respectively, while mothers that has just given birth to six children and above (P6>) has the least percentage and frequency of 9 and 6 respectively. 
Table 6 shows relationship between parity and previa. From the table, it can be deduced that the higher the parity the higher the risk of mother to previa.

\section{Discussion}

Reliable information on ultrasound study of the placenta positions is important for the management of pregnancy during parturition. It also assists the obstetricians in appropriately counselling women who are at risk of caesarean section. Ultrasonography is the best diagnostic process in the study of placenta because is highly reproducible and it is detected during first to third trimester gestation. It is well established that ultrasound study of the placenta position is significant in the processes of parturition.

This present study revealed that there is a significant relationship between placentas position and delivery. From table 2: talking about placenta positions and method of deliveries; the number of pregnant women who delivered normally out of 122 women irrespective of the placenta previa are 95 and caesarean sections are 27. This shows that a placenta position without previa does not affect parturition negatively. These cases of caesarean section were not due to placenta positions but as a result of complications in pregnancy such as, breech presentation, transverse presentation, eclampsia, intra uterine fetal death (IUFD), fetal distress/ failed labour, liquor drainage, women who had more than one caesarean section. This also revealed that anterior positioning of placenta is higher than other categories of placenta positions.

From table 3: Here the cases of previa were related to the type of delivery out of 28 cases of previa 18 women delivered by caesarean section and 10 had normal delivery. 10 out of all are previa type I, 7 are previa type II, and 11 are previa type III. All type III cases delivered through caesarean section, this support the work ofLeerentvel.et al., (9). In previa type I and type II, 7 and 3 cases respectively delivered normally and this also support the work of Townsend.et al., (10) which state that normal vaginal delivery can be expected in patient with low lying placenta (previa).

Table 4: revealed that there are most cases of previa in posterior placenta positions than that of anterior. 15 out of 28 previa cases are posterior and 13 are anterior. From table 6: it was also discovered that chances of previa increases as parity increases. In a total of 28 previa cases, P1 are $13(18.31 \%)$, P2 are $5(19.23 \%), \mathrm{P} 3$ are $3(17.64 \%), \mathrm{P} 4$ are 3(20\%), P5 are $2(16 \%)$ and $\mathrm{P} 6>$ are $2(22.22 \%)$. This shows that there is a relationship between parity and previa; this supports the work of Jilla (11). American pregnancy association; a study on the complications of pregnancy. However, grand - multiparity was noted in a significant proportion of the patient which may suggest its association with placenta previa as noted in other studies. Umezunike.et al., (12).

Conclusively, ultrasonographic study of the placenta position and its significant in parturition has been studied. This research work showed that there is significance relationship in the positioning of placenta and parturition among women in Delta state. Positions of placenta are a better predictor of method of delivery. According to Acona.et al., (13),placenta site (anterior or posterior) and the distance of the lower margin from the internal cervical os are important sonographic findings in predicting the mode of delivery in patients with placenta previa when detected early in the third trimester. The positions can either affect parturition positively or negatively depending on the relationship of the placenta site with internal cervical os. Operative delivery was indicated in all patients with placenta position covering the internal cervical os completely, while the group with placenta position away from the internal os delivered normally through the cervix, except with other factors that does not concerned placenta site.

It is therefore recommended that further studies should be done to confirm these findings in pregnant women with a bigger sample size.

\section{References}

[1]. Dubose TJ (1985).Fetal biometry, vertical carvarial diameter and carvarial volume"jornal of diagnostic medical sonography 1. (5): 205.

[2]. Brumers and Saddarth's. (Suzanne C. Smeltzer) Textbook of Medical surgical nursing (12 ${ }^{\text {th }}$ edition) p.g. 1413.

[3]. Shweni P.M. and moodley S.C (1986). Placenta grading by ultrasonograhphy as an index of fetal maturity Sam J; 70:525-528.

[4]. Petraglia F, Simoncini T, Florio P, Gallinelli A, Gremigni R, Volpe A, Genazzani A (1997). Placental stress factors and human parturition.Ann . N. Y. Acad. Sci.; 828:230-7.

[5]. Steer P, Flint C (1999). ABC of labour care: physiology and management of normal labour. BMJ, 318:793-796

[6]. Rehab K.H AL-jalili (2005). Epidemiology of ultrasound examinations during Antenatal care: frequency indication and outcome M.Sc, thesis, dept of community .Tikirt University: p7.

[7]. Ghourab S MD, Al-Jabari A MD (2000) .Placenta migration and mode of delivery in placenta previa: Transvaginalsonographic assessment during the third trimester.Ann Saudi ;Med;20(5-6):382-385.

[8]. Stedman's Medical dictionary. Copyright (2006).Llippincott Williams \& Wilkins

[9]. Leerentveld RA, Gilberts EC , Arnold MJ (1991). Accuracy and safety of transvaginalSonographic placental localization. ObstetGynecol .; 76: 759-761.

[10]. Townsend RP, Lang FC, Nyberg DA, (1986). Technical factors responsible for "placenta migration" sonographic assessment. Radiology, 160: 105-8.

[11]. Jilla (2010). American pregnancy association; a study on the complications of pregnancy.

[12]. Umezurike CC, Nkwocha G (2007). Placenta Accreta in Aba, south Easthern Nigeria, Niger J med; 16:219-222.

[13]. Acona S, Chatterjee M, Rhee I, Sicurenza B (1990). The midtrimester placenta previa a prospective follow up. EurJ Radiology; 10: 215-6. 